\title{
Mucormycosis Infections during the Second Wave of COVID-19: Experience from a Tertiary Care Centre in India
}

\author{
Sudhir BHANDARI', Shivankan KAKKAR², Amitabh DUBE ${ }^{3}$, Mohnish GROVER ${ }^{4}$, Shruti BHARGAVA ${ }^{5}$, Amit TAK ${ }^{6}$, \\ Bhoopendra PATEL ${ }^{7}$, Minal KACHHAWA ${ }^{3}$
}

\begin{abstract}
Background: Mucormycosis is an uncommon fungal infection with high morbidity and mortality. There had been a sudden surge in the cases of mucormycosis during the second wave of Coronavirus Disease 2019 (COVID-19) in India. Objective: The etiology, pathophysiology, and correlations of mucormycosis at tertiary hospital in India is explored in the present study. Methods: In this retrospective observational study, all coronavirus disease associated mucormycosis (CAM) cases admitted at this center between April 2021 to June 2021 were included. The cases were evaluated in terms of their background, most common presentations, chief underlying etiologies, severity of disease, comorbidities, investigation profiles, prognosis, and treatment provided. Results: Among the total 231 cases reported with mucormycosis, age group of 40 - 50 years (28\%) was the most afflicted and the 20-30 year was the least. Men (68\%) were more afflicted than Women. 66\% patients had a history of vaccination against COVID-19. 63\% patients presented with a High-Resolution Computerized Tomography (HRCT) score of 9-16. 60\% required oxygen support and $71 \%$ required steroids. Diabetes mellitus was the most prevalent comorbidity. Conclusion: The salience of the second inferno wave of COVID-19 was witness to COVID-19 patients who had pre-existing diabetes mellitus. Individuals with diabetes in general foster more extreme COVID-19 infections and end up using corticosteroids. In any case, the corticosteroids - alongside diabetes - increment the danger of getting mucormycosis. The specific pathophysiology of COVID-19 may represent co-morbidity with Invasive Fungal diseases (IFI).
\end{abstract}

Keywords: COVID-19, Coronavirus disease Associated Mucormycosis (CAM), Corticosteroids, Diabetes Mellitus, Second Wave.

\footnotetext{
'Department of Medicine, S. M. S. Medical College \& Attached Hospital, Jaipur, Rajasthan, India

${ }^{2}$ Department of Pharmacology, S. M. S. Medical College \& Attached Hospital, Jaipur, Rajasthan, India

${ }^{3}$ Department of Physiology, S. M. S. Medical College \& Attached Hospital, Jaipur, Rajasthan, India

${ }^{4}$ Department of ENT, S. M. S. Medical College \& Attached Hospital, Jaipur, Rajasthan, India

${ }^{5}$ Department of Pathology, S. M. S. Medical College \& Attached Hospital, Jaipur, Rajasthan, India

${ }^{6}$ Rajmata Vijaya Raje Scindia Medical College, Bhilwara, Rajasthan, India ${ }^{7}$ Department of Physiology, All India Institute of Medical Sciences (AlIMS),

Bilaspur, Himachal Pradesh, India
}

\section{Corresponding author.}

Bhoopendra PATEL, Department of Physiology, AlIMS, Bilaspur, Himachal Pradesh, India, 174001

E-mail: bhupendra.kool9999@gmail.com 


\section{INTRODUCTION}

The sphinx of the journey of Coronavirus Disease 2019 (COVID-19) has been puzzling and has left the medical fraternity dumbfounded and confounded. Similar to the practice of any disease process with mutable indications besetting people across the globe, the COVID-19 pandemic has seen a downpour of clashing data, which has come to be known as infodemic. COVID-19 has significantly challenged the frontiers of science, one after another wave testing the cutoff points through its limits. COVID-19 has horrified and dazed all alike taking the most viable available preventive guidelines for such rapidly evolving pandemic for a ride, more so for countries with high population density like India, where adhering to the laid down guidelines (that has been evolving with a better appreciation of the profile of SARS-CoV-2) has become a herculean task for all Governments across the Nation.

The first case of the COVID-19 was first reported from Wuhan City in China in December 2019.

The Chinese authorities later identified cases with the onset of symptoms in early December $2019{ }^{1}$. As of 10 June 2021, World Health Organization has registered 173,989,093 confirmed cases of COVID-19 with a mortality of 3,756,947 ${ }^{2}$. The Government of India has registered 1167952 active cases and 359676 deaths as of 10 June $2021^{3}$. Notwithstanding, the second wave of COVID-19 in India went with an epidemic of mucormycosis among COVID-19 infected and recovered patients. Mucormycosis (formerly known as zygomycosis) is uncommon contamination brought about by molds having a place with the subphylum Mucoromycotina in the order Mucorales ${ }^{4}$.

These fungi are omnipresent, especially in soil, rotting wood, and other natural matter ${ }^{5}$. Mucormycetes have an affinity for iron-rich, acidic conditions; ironover-burden states and acidemia are risk factors for disease. A classic element of mucormycosis is tissue putrefaction because of vascular intrusion and resulting thrombosis ${ }^{6,7}$. Before the pandemic, mucormycosis was at that point undeniably more common in India than in any other country. In the present second wave of COVID-19, most documented cases from India had been accounted for COVID-19 patients with diabetes mellitus or treatment with corticosteroids and antimicrobial agents. The prevalence of mucormycosis in India is approximately 0.14 cases per 1000 population, about 80 times the prevalence in developed countries ${ }^{8}$.
Even though mucormycosis overwhelmingly infects immunocompromised people, it has high morbidity and mortality. Data on the burden of the disease among COVID-19 patients in India stays insufficient. We should likewise acknowledge the way that COVID-19 comprises a high-risk population, not just because of the immunosuppression brought about by the viral infection itself, in addition to using certain prescriptions. Given the difficulty in diagnosis and the absence of explicit tests, the occurrence of fungal infections in patients with severe COVID-19 is most likely a lot higher than detailed in the scientific literature ${ }^{9}$. The present study aimed to feature

the etiology, pathophysiology, and relationships of Coronavirus disease Associated Mucormycosis (CAM) with other factors at Sawai Man Singh (SMS) Medical College Hospital, Jaipur in Rajasthan, India.

\section{MATERIALS \& METHODS}

In this retrospective descriptive observational study, all Coronavirus disease Associated Mucormycosis (CAM) cases admitted at this center between April 2021 to June 2021 were included. The salience of the second inferno wave of COVID-19 was witness to COVID-19 patients who had pre-existing diabetes mellitus or had been on protracted management protocol with corticosteroids and antimicrobial agents. The cases were studied for their background, most common presentations, chief underlying etiologies, severity of disease, comorbidities, investigation profiles, prognosis, and treatment provided.

The present study assessed this burden of mucormycosis and tried to look into a pattern of the cases and outcome of infection in our COVID-19 affected population. Continuous data were expressed as mean +/- standard deviation (minimum-maximum) while categorical data was expressed as statistical analysis numbers. The study has been approved by the Institutional Ethics Committee, SMS Medical College Hospital, Jaipur-302004, Rajasthan, India. Further, it has been carried out as per COVID-19 guidance of the Institute.

\section{RESULTS}

Table 1 shows the distribution of mucormycosis infection across age, gender, vaccination status against COVID-19, HRCT scores of patients, steam inha- 
lation used and oxygen support required. Among the total 231 cases reported with mucormycosis, the age group of $41-50$ years $(28 \%)$ was the most afflicted. It was followed by age groups of 51-60 year (26\%), 6170 year (21\%), 31-40 year (15\%), 70-80 year (7\%), 2130 year (3\%). The lowest prevalence was observed in the age group of 21-30 year. Gender data was available for 224 cases only, with more men (68\%) afflicted than women (32\%). Vaccination status was available for 41 cases, and only $66 \%$ patients had a history of vaccination against COVID-19. HRCT scores were available for 30 patients only. Out of these maximum (63\%) patients presented with a score of $9-16$, followed by $23 \%$ and $13 \%$ with a score between $0-8$ and more than 16 , respectively. Out of data available for 23 patients, 39\% had a history of steam inhalation. The data regarding oxygen requirement was available for 188 patients only. $60 \%$ of these patients required oxygen support.

Table 1. Distribution of attributes in patients of mucormycosis

\begin{tabular}{|c|c|c|c|c|c|c|}
\hline \multirow{2}{*}{ Variable } & \multirow{2}{*}{ Level } & \multirow{2}{*}{ Counts } & \multirow{2}{*}{ Total } & \multirow{2}{*}{ Percent } & \multicolumn{2}{|c|}{$95 \% \mathrm{CI}$} \\
\hline & & & & & $\mathbf{L L}$ & UL \\
\hline \multirow{6}{*}{ Age group } & 20 to 30 & 8 & 231 & 3.5 & 1.5 & 6.7 \\
\hline & 30 to 40 & 34 & 231 & 14.7 & 10.4 & 20 \\
\hline & 40 to 50 & 65 & 231 & 28.1 & 22.4 & 34.4 \\
\hline & 50 to 60 & 60 & 231 & 26 & 20.4 & 32.1 \\
\hline & 60 to 70 & 48 & 231 & 20.8 & 15.7 & 26.6 \\
\hline & 70 to 80 & 16 & 231 & 6.9 & 4 & 11 \\
\hline \multirow{2}{*}{ Gender } & Women & 71 & 224 & 31.7 & 25.7 & 38.2 \\
\hline & Men & 153 & 224 & 68.3 & 61.8 & 74.3 \\
\hline \multirow{2}{*}{ Vaccination History } & Absent & 27 & 41 & 65.9 & 49.4 & 79.9 \\
\hline & Present & 14 & 41 & 34.1 & 20.1 & 50.6 \\
\hline \multirow{3}{*}{ HRCT score } & 0 to 8 & 7 & 30 & 23.3 & 9.9 & 42.3 \\
\hline & 9 to 16 & 19 & 30 & 63.3 & 43.9 & 80.1 \\
\hline & Greater than 16 & 4 & 30 & 13.3 & 3.8 & 30.7 \\
\hline \multirow{2}{*}{$\begin{array}{l}\text { History of Steam Inha- } \\
\text { lation }\end{array}$} & Absent & 14 & 23 & 60.9 & 38.5 & 80.3 \\
\hline & Present & 9 & 23 & 39.1 & 19.7 & 61.5 \\
\hline \multirow{2}{*}{ Oxygenation } & Absent & 75 & 188 & 39.9 & 32.8 & 47.3 \\
\hline & Present & 113 & 188 & 60.1 & 52.7 & 67.2 \\
\hline
\end{tabular}


Table 2. District wise distribution of mucormycosis cases

\begin{tabular}{|c|c|c|c|c|}
\hline \multicolumn{3}{|c|}{ Frequencies for District $(\mathrm{N}=194)$} & \multicolumn{2}{|c|}{$95 \% \mathrm{CI}$} \\
\hline District & Frequency & Valid Percent & $\mathbf{L L}$ & UL \\
\hline Baran & 1 & 0.515 & 0.013 & 2.8 \\
\hline Bundi & 1 & 0.515 & 0.013 & 2.8 \\
\hline Dausa & 3 & 1.546 & 0.3 & 4.5 \\
\hline Ganganagar & 3 & 1.546 & 0.3 & 4.5 \\
\hline Hanumangarh & 8 & 4.124 & 1.8 & 8 \\
\hline Jhalawar & 4 & 2.062 & 0.6 & 5.2 \\
\hline Jhunjhunu & 8 & 4.124 & 1.8 & 8 \\
\hline Karouli & 1 & 0.515 & 0.013 & 2.8 \\
\hline Sikar & 15 & 7.732 & 4.4 & 12.4 \\
\hline Ajmer & 5 & 2.577 & 0.8 & 5.9 \\
\hline Alwar & 24 & 12.371 & 8.1 & 17.8 \\
\hline Bharatpur & 6 & 3.093 & 1.1 & 6.6 \\
\hline Bhilwara & 9 & 4.639 & 2.1 & 8.6 \\
\hline Bikaner & 2 & 1.031 & 0.1 & 3.7 \\
\hline Chittorgarh & 4 & 2.062 & 0.6 & 5.2 \\
\hline Churu & 8 & 4.124 & 1.8 & 8 \\
\hline Jaipur & 72 & 37.113 & 30.3 & 44.3 \\
\hline Kota & 7 & 3.608 & 1.5 & 7.3 \\
\hline Nagaur & 8 & 4.124 & 1.8 & 8 \\
\hline Sirohi & 1 & 0.515 & 0.013 & 2.8 \\
\hline Tonk & 4 & 2.062 & 0.6 & 5.2 \\
\hline
\end{tabular}

Table 2 shows the district wise distribution of mucormycosis patient load $(n=194)$ at tertiary level health care centre of Rajasthan. The maximum number of cases were observed in Jaipur ( $n=72)$, followed by Alwar $(n=24)$ and Sikar $(n=15)$. The remaining district had a patient load of less than 10 cases in each district.

Table 3. Distribution of co-morbidities in patients of mucormycosis $(\mathrm{N}=201)$

\begin{tabular}{lcccc}
\hline \multirow{2}{*}{ Variable } & \multirow{2}{*}{ Frequency } & Percent & LL & UL \\
\hline DM & 171 & 85.1 & 79.4 & 89.7 \\
Hypertension & 48 & 23.9 & 18.2 & 30.4 \\
Renal Disease & 5 & 2.5 & 0.8 & 5.7 \\
Cancer & 2 & 1 & 0.1 & 3.5 \\
CVD & 4 & 2 & 0.5 & 5 \\
Others & 8 & 4 & 1.7 & 7.7 \\
No Comorbidities & 15 & 7.5 & 4.2 & 12 \\
\hline
\end{tabular}

Table 3 shows distribution of comorbidities observed in 201 mucormycosis patients. Diabetes mellitus was the most prevalent comorbidity $(\mathrm{n}=171)$, followed by hypertension $(n=48)$, renal disease $(n=5)$, cardiovascular disease $(n=4)$, cancer $(n=2)$ and others $(n=8)$. However, 15 patients had no associated comorbidity.

\section{DISCUSSION}

There has been a spurt in the cases of mucormycosis among COVID-19 patients in Rajasthan. The management of Mucorales infection is itself quite challenging. Individuals with diabetes in general foster more extreme COVID-19 infections and end up using corticosteroids. In any case, the corticosteroids - alongside diabetes - increment the danger of getting mucormycosis. The specific pathophysiology of COVID-19 may likewise represent extraordinary co-morbidity with Invasive Fungal diseases (IFI). The highly aggressive element of the SARS-CoV-2 infection to the lung tissue and the enormous bilateral alveolo-interstitial lesions make the event of IFI likely, explicitly those with a primary pulmonary entry and an airborne route of infection like invasive pulmonary aspergillosis (IPA), pneumocystosis and mucormycosis ${ }^{10}$.

An absolute number of T lymphocytes, CD4+T, and $\mathrm{CD} 8+\mathrm{T}$ cells are particularly lower in extreme COVID-19 cases than moderate cases, related to especially more significant levels of Interleukins: IL-2R, IL-6, IL-10, Tumor Necrosis Factor TNF-alpha, and some other inflammatory markers ${ }^{11}$. The role that the Angiotensin Converting Enzyme 2 (ACE2) receptor plays in contributing to the hemostatic anomalies found in Severe Acute Respiratory Syndrome Coronavirus 2 (SARS-CoV-2) disease remains to be completely clarified. It is obscure whether SARS-CoV-2 can prompt abnormal coagulation by attacking vascular endothelial cells expressing high levels of ACE2 ${ }^{12}$.

The mucormycosis ordinarily gains entry through the respiratory tract and displays an exceptional affinity for arteries. It attacks the arteries, structures thrombi inside the blood vessels that decrease blood supply and cause necrosis of hard and delicate tissues ${ }^{13}$. There is inadequate proof concerning whether infection with COVID-19 worsens the improvement of the development of acute arterial/ microvascular thrombosis and ensuing mucormycosis. Ravani et al. suggested uncontrolled diabetes with concomitant steroid use as a significant risk factor for mucormycosis in COVID-19 patients. Moreover, the presence of cerebral involve- 
ment and an $\mathrm{HbA} 1 \mathrm{c}$ value of $\geq 8$ was significant in the prediction of survival of patients with mucormycosis ${ }^{14}$.

Metabolic control improves outcomes related to mucormycosis, R. oryzae proliferation was higher among diabetic people, including good glycemic control than among non-diabetic people ${ }^{15}$. Notwithstanding, as per certain researchers, the mucormycosis cases might be identified with the country's profoundly infectious coronavirus variant, as opposed to diabetes mellitus or abuse of steroids or antimicrobial agents. There is a solid sign that this variant could be capable - primarily because different regions reported different numbers of mucormycosis regardless of having comparable infections of COVID-19. It is being speculated that the new variant, known as „Delta” or B.1.617.2, is making exceptional damage to the pancreas of otherwise healthy individuals, setting off sudden onset diabetes and soaring blood glucose levels. Nonetheless, a unique variant can cause more disruption of the lining of the nose or the lungs, and then that would allow the fungus to get in more easily. In any case, it is somewhat tenuous. More research is needed to comprehend the causal relationship between the delta variant, uncontrolled diabetes, mucormycosis, and other likely results. By far, the most acknowledged speculation is that it is the mix of diabetes and high-dose steroids that is driving the current plague of mucormycosis cases. Each is known to be an autonomous risk factor for mucor.
In COVID-19 the primary organ of affection has been the respiratory system. Impact on different systems has been variable, and a few associations have been reported based on clinical observations. While the pancreatic injury might be found in specific patients with COVID-19, acute pancreatitis is exceptional. Various reports have been circulated referring to that gastrointestinal side effects are regular in patients with COVID-19 disease. It has likewise been tracked down that the ACE2 receptor of SARS-CoV-2 is expressed more in the pancreas than in the lungs. Little consideration has been paid to the degree of pancreatic injury brought about by COVID-19. Lack of awareness regarding the COVID-19 status of patients presenting pancreatitis may expose health care workers to SARS-CoV-2 while performing interventions to oversee complications of pancreatitis ${ }^{16}$.

Albeit no causal relationship has been set up, a temporal relationship among pancreatitis and COVID-19 is emphatically demonstrative of SARS-CoV2 -prompted injury. Significantly, the vast majority of these cases have been reported in moderate or severe illness. Patnaik et al. have proposed that the pathophysiology of pancreatitis could be based on systemic inflammatory response as opposed to a direct cytopathological impact ${ }^{17}$. Acute pancreatitis isn't explicitly brought about by SARS-CoV-2; it is a typical disease with numerous causes, and the etiology stays obscure

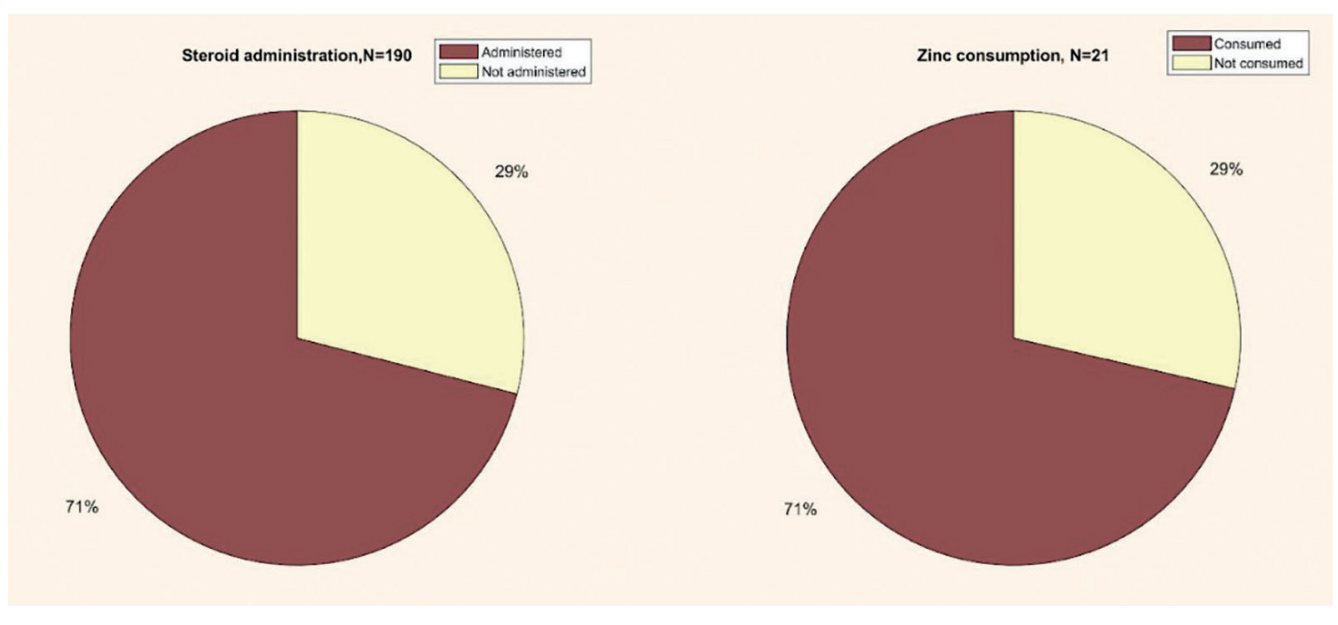

Figure 1. Pie charts show the percentage of the steroid administration and zinc consumption in mucormycosis patients.

Figure 1 shows the pie chart depicting steroid requirement and zinc prescription status in Mucormycosis patients. Data of 190 subjects concerning treatment was available and it showed that $71 \%$ patients required steroids. $71 \%$ patients had history of zinc consumption out of 21 patients whose data was available. 
in $15-25 \%$ of cases ${ }^{18}$. Animal models of COVID-19 contributing to acute pancreatitis are also deficient ${ }^{19}$.

Additional factors that may drive mucormycosis infections are that numerous patients get Azithromycin and doxycycline from the get-go throughout the COVID-19 infection. When that fails, patients often receive other broad-spectrum antimicrobial agents and steroids. Normal bacteria are wiped out, leaving just multidrug-resistant microbes, yeast, or parasites. It is a reminder for the utilization of strict evidence-based guidelines to battle COVID-19 with its co-morbidities and from unseen consequences of fungal infections. Concern was also raised over use of industrial oxygen for medical use in India amid oxygen crisis due to sudden surge in COVID-19 cases. Experts believed that routine use of corticosteroids in rheumatology patients didn't lead to such a high prevalence of mucormycotic cases. However, the association of the mucormycosis surge in COVID-19 patients in second wave still remains debatable and needs further elucidation ${ }^{20}$.

\section{CONCLUSION}

Individuals with diabetes in general foster more extreme COVID-19 infections and end up using corticosteroids. In any case, the corticosteroids - alongside diabetes - increment the danger of getting Coronavirus disease Associated Mucormycosis (CAM). The specific pathophysiology of COVID-19 may likewise represent extraordinary co-morbidity with Invasive Fungal diseases (IFI). It would indeed be an interesting precept to explore the relationship of delta variant of SARS$\mathrm{CoV}-2$, its antecedent pancreatic injury (through the action of furine protease, an enzyme present in the pancreas that cleaves unique site of SARS-CoV-2), pancreatic injuries, microangiopathic thrombi, uncontrolled diabetes, mucormycosis, and another yet unprecedented outcome.

COVID-19 has enormously affected on health and finances of developed and developing nations to a degree not seen previously and this might have been the impetus for medicines and vaccines being developed so rapidly. What lays ahead nobody knows, yet what we do realize that there is a promising culmination of current circumstances.

Abbreviation: COVID-19: Coronavirus Disease 2019; SMS: Sawai Man Singh; CAM: Coronavirus disease Associated Mucormycosis; HRCT: High-Resolution
Computerized Tomography; CVD: Cardiovascular Disease; IFI: Invasive Fungal Diseases; IPA: Invasive Pulmonary aspergillosis (IPA); IL: Interleukins; TNF alpha: Tumor Necrosis Factor alpha; ACE2: Angiotensin Converting Enzyme 2; SARS-CoV-2: Severe Acute Respiratory Syndrome Coronavirus 2

Compliance with ethics requirements: The authors declare no conflict of interest regarding this article. The authors declare that all the procedures and experiments of this study respect the ethical standards in the Helsinki Declaration of 1975, as revised in 2008(5), as well as the national law. Informed consent was obtained from all the patients included in the study 


\section{References}

1. Wang C, Horby PW, Hayden GF, Gao GF. A novel coronavirus outbreak of global health concern. The Lancet. 2020;395(10223): 470-473. https://doi.org/10.1016/S0140-6736(20)30185-9

2. World Health Organization (WHO). WHO Coronavirus (COVID-19) Dashboard. Available from: https://covid19.who.int/ [Accessed on 10 June 2021].

3. Ministry of Health and Family Welfare, Government of India. Available from: https://www.mohfw.gov.in/\# [Accessed on 10 June 2021].

4. Hibbett DS, Binder M, Bischoff JF, Blackwell M, Cannon PF, Eriksson $\mathrm{OE}$ et al. A higher-level phylogenetic classification of the Fungi. Mycol Res. 2007;111: 509-47. https://doi.org/10.1016/j. mycres.2007.03.004

5. Antoniadou A. Outbreaks of zygomycosis in hospitals. Clin Microbiol Infect. 2009;15(Suppl 5):55-9. https://doi.org/10.1111/ j.1469-0691.2009.02982.x

6. Sun HY, Singh N. Mucormycosis: its contemporary face and management strategies. Lancet Infect Dis 2011;11(4):301-11. https:// doi.org/10.1016/s1473-3099(10)70316-9

7. Skiada A, Petrikkos G. Cutaneous zygomycosis. Clin Microbiol Infect. 2009; 15 (Suppl 5):41-5. https://doi.org/10.1111/j.14690691.2009.02979.x

8. Skiada A, Pavleas I, Drogari-Apiranthitou M. Epidemiology and diagnosis of mucormycosis: An update. J Fungi (Basel). 2020; 6(4): 265. https://dx.doi.org/10.3390\%2Fjof6040265

9. Segrelles-Calvo G, de S Araújo GR, Frases S. Systemic mycoses: a potential alert for complications in COVID-19 patients. Future Microbiol. 2020;15:1405-1413. https://doi.org/10.2217/fmb2020-0156

10. He F, Deng Y, Li W. Coronavirus disease 2019 (COVID-19): what we know? J Med Virol. 2020;92(7):719-725. https://doi.org/10.1002/ jmv. 25766

11. Chen G, Wu D, Guo W, Cao Y, Huang D, Wang H et al. Clinical and immunologic features in severe and moderate Coronavirus disease 2019. J Clin Invest. 2020;130(5):2620-2629. https://doi. org/10.1172/jci137244
12. Hamming I, Timens W, Bulthuis ML, Lely AT, Navis G, van Goor $H$. Tissue distribution of ACE2 protein, the functional receptor for SARS coronavirus. A first step in understanding SARS pathogenesis. J Pathol. 2004;203(2):631-7. https://doi.org/10.1002/ path.1570

13. Gupta S, Goyal R, Kaore NM. Rhino-Orbital-Cerebral Mucormycosis: Battle with the Deadly Enemy. Indian J Otolaryngol Head Neck Surg. 2020;72(1):104-11. https://doi.org/10.1007/s12070019-01774-Z

14. Ravani SA, Agrawal GA, Leuva PA, Modi PH, Amin KD. Rise of the phoenix: Mucormycosis in COVID-19 times. Indian J Ophthalmol. 2021;69(6):1563-1568. https://doi.org/10.4103/ijo.ijo_310_21

15. Salazar-Tamayo G, López-Jácome LE, Resendiz-Sanchez J, Franco-Cendejas R, Rodriguez-Zulueta P, Corzo-León DE. Higher In vitro Proliferation Rate of Rhizopus oryzae in Blood of Diabetic Individuals in Chronic Glycaemic Control Compared with Non-diabetic Individuals. Mycopathologia. 2017;182(11-12):1005-1014. https://doi.org/10.1007/s11046-017-0174-0

16. Kumaran NK, Karmakar BK, Taylor OM. Coronavirus disease-19 (COVID-19) associated with acute necrotizing pancreatitis (ANP). BMJ Case Reports CP 2020;13:e237903. http://dx.doi. org/10.1136/bcr-2020-237903

17. Patnaik RNK, Gogia A, Kakar A. Acute pancreatic injury induced by COVID-19. ID Cases. 2020;22:e00959. https://doi.org/10.1016/j. idcr.2020.e00959

18. Boxhoorn L, Voermans PR, Bouwense SA, Bruno MJ, Verdonk $\mathrm{RC}$, Boermeester MA et al. Acute pancreatitis. The Lancet. 2020;396 (10252):726-734. https://doi.org/10.1016/S01406736(20)31310-6

19. de-Madaria, E., Capurso, G. COVID-19 and acute pancreatitis: examining the causality. Nat Rev Gastroenterol Hepatol. 2021;18:34. https://doi.org/10.1038/s41575-020-00389-y

20. Black fungus: Experts flag role of industrial Oxygen. The Tribune. 22 May 2021. Available from: https://www.tribuneindia.com/ news/nation/black-fungus-experts-flag-role-of-industrial-oxygen-256498. [Accessed on 10 June 2021]. 